\title{
MATERNAL FACTORS ASSOCIATED WITH LOW BIRTH WEIGHT AMONG THE DELIVERIES IN A SIR SUNDER LAL HOSPITAL, BHU, VARANASI
}

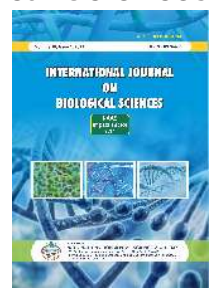

\author{
Ruchi Kannaujiya ${ }^{1}$, Usha Srivastava ${ }^{2}$ and Alok Kumar ${ }^{3}$
}

${ }^{1}$ Department of Statistics, Institute of Science, Banaras Hindu University, Varanasi, Uttar Pradesh ${ }^{2} \mathrm{MMV}$, Statistics Section, Institute of Science, Banaras Hindu University, Varanasi, Uttar Pradesh ${ }^{3}$ Department of Statistics, Institute of Science, Banaras Hindu University, Varanasi, Uttar Pradesh

\section{Research Paper}

\section{ABSTRACT}

\begin{abstract}
Birth weight is very important indicator of the health and viability of a newborn infant. It is a significant factor of newborn growth and survival. Globally, it is estimated that there are 20 million of infants who are born with low birth weight, it depends on many maternal factors such as maternal age, gestations, antenatal care, education level, weight gain, parity, sex of child, and body mass index. Logistic regression is a statistical model for analyzing a dataset in which one or more independent variables that determine an outcome. The main objective of this paper is to identify the predictors of low birth weight through binary logistic regression model.
\end{abstract}

Methods: A hospital based cross sectional study was conducted in Obstetrics and Gynecology postnatal ward of Sir Sunder Lal hospital, BHU, Varanasi from 14th June 2015 to 15 January 2017. Altogether 500 respondents were taken and respondents were Mother who had delivered the newborns in SSL hospital. A spring type weighing machine scale was used to measure the birth weight of babies and birth weight was taken after the birth within the 24 hours.

Result: A total of 517 births occurred during the study period among which $39.07 \%$ were low birth weight and 60.93\% were normal birth weight. Low birth weight neonates mean birth weight was found to be $1.93 \mathrm{~kg}$ and overall the mean in birth weight was $2.97 \mathrm{~kg}$. Chi square test to find out the risk factor associated with the low birth weight which shows that maternal education, initial weight of mother, weight gain of mother, gestation, sex of child, pregnancy complication, body mass index, antenatal care are statistically significant with low birth weight. The fitted binary Logistic regression model shows that use of iron and calcium supplements has the highest odd ratio compared to the other factors.

Conclusion: This study suggest that there were several factors finding to affect the birth weight which are education level, maternal weight, weight gain, body mass index, antenatal care, sex of neonates, pregnancy complication, gestation age and use of iron calcium supplements.

Keywords: Low Birth weight, maternal risk factors, pregnancy.

\section{INTRODUCTION}

Birth weight is a potent predictor of infant growth and existence. Infants born with LBW always deal with detriments from the commencement of their life and face extremely poor survival, which can cause neonatal mortalities. According to the World Health Organization (WHO), 31\% of neonatal deaths could be accredited to preterm birth (PTB) and LBW has been defined by the WHO as weight at birth of less than $2.5 \mathrm{~kg}$. Even though the LBW is a major health issue in developing countries, mandatory

*Corresponding author: ruchi.kannaujiya@gmail.com 
and satisfied actions have not been taken yet to completely overcome this issue. The determinants associated with this foremost problem are such as maternal age, Education level, maternal weight, weight gain and body mass index (BMI), antenatal care, parity, marriage duration, pregnancy complication,, mode of delivery and some other factors. The primary reason of low birth weight is premature birth (birth before 37 weeks gestation). Being born early means a baby will be in the mother's uterus for a short period of time than usual deliveries. So, baby has a fewer period to grow and gain weight as considerable amount of a baby's weight is gained during the ultimate portion of pregnancy.

Several studies showed that maternal factor affect LBW such as Ravi Kumar Bhaskar et al. (2015) was examined the case control study on risk factor associated with low birth babies . They collected 318 sample from two hospital during September 2011 to February 2012 by using interview technique. They found $50 \%$ birth was LBW babies in their studies. He found that delay age at first pregnancy, improving maternal education and nutrition and iron and calcium supplement, any illness during pregnancy as the significant predictors of low birth weight. Another similar study by Sri eka Purwanengsi et al . (2016) was finding that the age of mother, gestational age, parity and low hemoglobin level affect the low birth weight.

In addition to this, Kamal Prasad Kandel et al. (2017) was conducted cross sectional study on birth weight among deliveries at Bharatpur hospital they found that there were several factor , which lead to low birth weight babies which are age of mother at delivery, maternal education, weight gain by mother during pregnancy maternal height, low body mass index. Aboobucker Haalisha et al. (2018) was used Logistic regression methods for assessing the contributing factors of low birth weight and they found that maternal age, maternal education, maternal weight, weight gain during pregnancy, parity had associated factors of LBW and the passive smoking had the most important risk factor for the low birth weight. Priyanka Anand et al. (2019) was found that the prevalence of low birth weight was $28.8 \%$ and age of mothers, maternal education and rest received in the afternoon during pregnancy were statistically significant with low birth weight. Furthermore, Maheshwari K. (2020) was discussed the regular antenatal check up, preterm pregnancy, avoidance of teenage and elderly pregnancy, proper iron tablet intake are the important risk factor of low birth weight babies.

\section{Methodology \\ Objective}

This study has been identified the socio demographic and maternal factors that highly associated with LBW and also to estimate the proportion of LBW neonates among institutional deliveries.

\section{Data collection method and sample size}

A hospital-based cross sectional study was conducted in Obstetrics and Gynecology ward of Sir Sunder Lal hospital, BHU, Varanasi from 14th June 2015 to 15 January 2017 .Altogether 500 respondents were taken and respondents were Mother who had delivered the newborns in SSL hospital. Result a total birth occurred during the study period of which met the study criteria among which were low birth weight and were normal birth . The information was collected using pre design structured questionnaire which includes socio demographic and maternal factors. A spring type weighing machine scale was used to measure the birth weight of babies and birth weight was taken after the birth within the 24 hours. First questionnaire was completed then thoroughly by the researcher himself. Data was coded compile and analyze in statistical packages for social science (SPSS) version 21 software.

\section{Study variables}

The dependent variable of this study is " Birth weight" which has two binary outcomes if a neonate is normal birth weight coded as ' 0 ' and If a neonate is low birth weight coded as ' 1 '. The predictor variables consider maternal age, education level, maternal weight, weight gain and body mass index (BMI), antenatal care, parity, marriage duration, pregnancy complication, gestation and some other factors.

\section{Statistical analysis}

The data analysis included univariate, bivariate and multivariate analysis. In the univariate analysis descriptive statistics (mean and standard deviation) used to explain the variables. In bivariate analysis we illustrate the distribution between the dependent and the independent variables. Multivariate logistic regression analysis used to estimate the effect of independent variable on dichotomous dependent variables. The logistic regression analyses were performed to estimate and identify the maternal factors associated with neonatal birth weight. The logistic function is 


$$
p=\frac{1}{1+\exp (-y)}=\frac{\exp (y)}{1+\exp (-y)}
$$

Let us suppose that $y$ instead of being a single predictor variable, is a linear combination of a set of predictor variables, i.e.

$$
=b_{0}+b_{1} x_{1}+b_{2} x_{2}+b_{3} x_{3} \ldots . .+b_{k} x_{k}
$$

Therefore

$$
p=\frac{1}{1+\exp \left[\left[-\left(b_{0}+b_{1} x_{1}+b_{2} x_{2}+\cdots+b_{k} x_{k}\right)\right]\right.}
$$

So, that

$$
1-p=\frac{\left.\exp \text { 玮 }-\left(b_{0}+b_{1} x_{1}+b_{2} x_{2}+\cdots+b_{k} x_{k}\right)\right]}{\left.1+\exp \text { 象 }-\left(b_{0}+b_{1} x_{1}+b_{2} x_{2}+\cdots+b_{k} x_{k}\right)\right]}
$$

$$
\text { Hence, odds }
$$

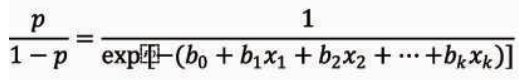

$$
\begin{aligned}
& =\exp \left[\left(b_{0}+b_{1} x_{1}+b_{2} x_{2}+\cdots+b_{k} x_{k}\right)\right] \\
& \operatorname{Ln} \text { (odds) }=\left(b_{0}+b_{1} x_{1}+b_{2} x_{2}+\cdots+b_{k} x_{k}\right) \\
& \operatorname{Ln}\left[\frac{\mathrm{p}}{1-\mathrm{p}}\right]=\beta_{0}+\beta_{1} x_{1}
\end{aligned}
$$

Hence, odds

where $p$ is the probability of an event occurring, 1-p is the probability of the other decision, $\mathrm{x}$ is our predictor variable, and $\beta_{0}$ estimates the $\log$ odds and $\beta$ estimates the maximum likelihood, the differential log odds of birth weight of neonates among the women associated with the predictor x. For neonatal birth weight status three models were generated as:

a. Model I with socio-demographic characteristic

b. Model II with maternal reproductive health factors

c. Model III with maternal antenatal care behaviour.

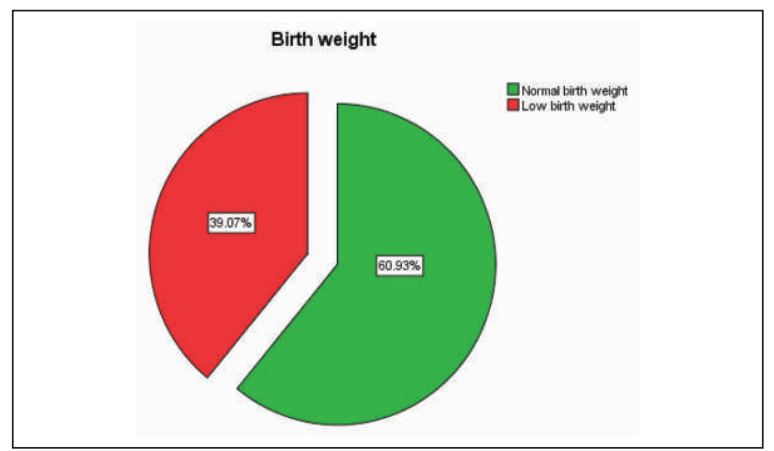

Figure 1: Proportion of low birth weight neonates.

From figure 1: It is clear that low birth weight neonates are $1.56 \%$ greater than that of normal birth weight neonates. In the study, mean birth weight of LBW neonates was $1.93 \mathrm{~kg}$ with SD of $0.443 \mathrm{~kg}$.

Table1: Descriptive Statistics of the factors affecting LBW.

\begin{tabular}{|l|c|c|}
\hline Variables & Mean & Standard Deviation \\
\hline Age (in years) & 26.12 & 4.462 \\
\hline Initial Weight (in $\mathrm{kg})$ & 54.20 & 3.827 \\
\hline Weight Gain (in kg) & 4.33 & 1.397 \\
\hline Height (in cm) & 155.87 & 4.526 \\
\hline BMI $\left(\mathrm{kg} / \mathrm{m}^{2}\right.$ ) & 22.37 & 2.084 \\
\hline Total No. of ANC & 2.92 & 0.758 \\
\hline Gestation (in weeks) & 2.33 & 0.657 \\
\hline Parity & 1.84 & 0.878 \\
\hline Pregnancy complication & 0.28 & 0.449 \\
\hline
\end{tabular}

Table 1: The data included 517 live single and multiple deliveries This study 191 mothers with LBW, and the mean age was $26.12( \pm 4.462)$ years and range between 19 years and 43 years and the mean of maternal weight was $54.2( \pm 3.827) \mathrm{kgs}$ and height was 155.87 ( $( \pm 4.526)$ cms. Maternal weight gain during pregnancy mean was 4.33(( \pm 1.397$)$ kgs and maternal BMI mean was $22.37\left( \pm 2.084\left(\mathrm{~kg} / \mathrm{m}^{2}\right)\right.$. The mean parity was $1.84( \pm$ 
$0.878)$ and the mean Gestation age was 2.33( \pm 0.657$)$ weeks and it ranged between 32 and 43 gestational weeks and the mean number of antenatal visit by mother was 2.33 visits which indicate that minimum 2 antenatal visit by mother before birth of neonates. Similar studies done by Lumbani T et al.(2019) for Tshwane district South Africa, they found age of mother who delivered low birth weight infants was
$24.22( \pm 5.11)$ years and mean gestational age at birth was 35.60 ( \pm 3.75$)$ weeks. Similar results were obtained from the studies done by Ravi kumar bhaskar et al. mean of low birth weight infants was 2126.73 $( \pm 340.13) \mathrm{gm}$ and mean age of mother who delivered low birth weight infants was $24.07( \pm 5.09)$ years and mean of maternal weight was $47.04( \pm 9.30) \mathrm{kg}$ and height was $146.73( \pm 7.88) \mathrm{cm}$, total ANC visit by

Table 2: Distribution of women with low and normal birth weight of Socio-demographic characteristic.

\begin{tabular}{|c|c|c|c|}
\hline Variables & $\begin{array}{c}\text { Low Birth } \\
\text { Weight (LBW) }\end{array}$ & $\begin{array}{l}\text { Normal Birth } \\
\text { Weight (NBW) }\end{array}$ & $\chi^{2}$ \\
\hline \multicolumn{4}{|c|}{ Educational Qualification of mother } \\
\hline High school & $71(35.1 \%)$ & $79(25.1 \%)$ & \multirow{4}{*}{$\begin{array}{c}16.544 \\
(0.001)^{* *}\end{array}$} \\
\hline Intermediate & $47(23.3 \%)$ & 119 (37.8\%) & \\
\hline $\begin{array}{l}\text { Graduate \& Professional } \\
\text { degree }\end{array}$ & $71(35.1 \%)$ & $86(27.3 \%)$ & \\
\hline Post graduate \& above & $13(6.4 \%)$ & $31(9.8 \%)$ & \\
\hline \multicolumn{4}{|c|}{ Educational Qualification of father } \\
\hline High school & $39(19.3 \%)$ & $54(17.1 \%)$ & \multirow{4}{*}{$\begin{array}{c}8.472 \\
(0.037)^{*}\end{array}$} \\
\hline Intermediate & $61(30.2 \%)$ & $77(24.4 \%)$ & \\
\hline $\begin{array}{l}\text { Graduate \& Professional } \\
\text { degree }\end{array}$ & $77(38.1 \%)$ & $159(50.5 \%)$ & \\
\hline Post graduate \& above & $25(12.4 \%)$ & $25(7.9 \%)$ & \\
\hline \multicolumn{4}{|l|}{ Occupation of father } \\
\hline Student & $24(11.9 \%)$ & $27(8.6 \%)$ & \multirow{4}{*}{$\begin{array}{c}10.886 \\
(0.012)^{*}\end{array}$} \\
\hline Private job or Business & $131(64.9 \%)$ & $205(65.1 \%)$ & \\
\hline Government job & $20(9.9 \%)$ & $58(18.4 \%)$ & \\
\hline Daily wage worker & $27(13.4)$ & $25(7.9 \%)$ & \\
\hline \multicolumn{4}{|l|}{ Family Income } \\
\hline Less than 10000 & $49(24.3 \%)$ & $59(18.7 \%)$ & \multirow{4}{*}{$\begin{array}{c}4.038 \\
(0.257)\end{array}$} \\
\hline $10000-15000$ & $36(17.8 \%)$ & $50(15.9 \%)$ & \\
\hline 15000-20000 & $54(26.7 \%)$ & $84(26.7 \%)$ & \\
\hline 20000 \& Above & $63(31.2 \%)$ & $122(38.7 \%)$ & \\
\hline
\end{tabular}

Statistical significance : $* * * \mathrm{P}<.001,{ }^{* *} \mathrm{p}<.01,{ }^{*} \mathrm{p}<.05$

Table 2 shows the distribution of women by their neonatal birth weight status proportion with low birth weight and normal birth weight baby with respect to selected characteristics the result shows that the relationship between selected variable and neonatal birth weight is significant except family income. There was a significant Association between education level of mothers and low birth weight neonates table 2 explain that about $35.1 \%$ of mothers of low birth weight neonates had high School, $23.3 \%$ had an 
education of intermediate and above and also significant association between education level of fathers and low birth weight neonates, about $19.3 \%$ of fathers of low birth weight neonates had high School,
$30.2 \%$ had an education of intermediate and above. The proportion of father's with low birth weight neonates was doing private job, was higher than that of father's doing government job and daily wage worker.

Table 3: Distribution of Neonate birth weight and maternal characteristics.

\begin{tabular}{|c|c|c|c|}
\hline Characteristics & $\begin{array}{c}\text { Low Birth } \\
\text { Weight (LBW) }\end{array}$ & $\begin{array}{l}\text { Normal Birth } \\
\text { Weight (NBW) }\end{array}$ & $\chi^{2}$ \\
\hline \multicolumn{4}{|c|}{ Maternal Age (in years) } \\
\hline $19-23$ & $61(30.2 \%)$ & $75(23.8 \%)$ & \multirow{4}{*}{$\begin{array}{l}5.234 \\
(0.15)\end{array}$} \\
\hline $24-28$ & 87 (43.1\%) & $167(53.0 \%)$ & \\
\hline $29-33$ & 39 (19.3\%) & $50(15.9 \%)$ & \\
\hline 34 and above & $15(7.4 \%)$ & $23(7.3 \%)$ & \\
\hline \multicolumn{4}{|l|}{ Sex of child } \\
\hline Male & $91(45 \%)$ & $175(55.6 \%)$ & \multirow{2}{*}{$\begin{array}{l}5.438 \\
(0.02)^{*}\end{array}$} \\
\hline Female & $111(55 \%)$ & $140(44.4 \%)$ & \\
\hline \multicolumn{4}{|l|}{ Parity of Mothers } \\
\hline $\mathrm{P}<3$ & $158(78.2 \%)$ & $244(77.5 \%)$ & \multirow{2}{*}{$\begin{array}{l}0.041 \\
(0.84)\end{array}$} \\
\hline $\mathrm{P} \geq 3$ & $44(21.8 \%)$ & $71(22.5 \%)$ & \\
\hline \multicolumn{4}{|c|}{ Initial weight of Mothers (kg) } \\
\hline $\mathrm{WOM} \leq 50$ & $34(16.8 \%)$ & $23(7.3 \%)$ & \multirow{3}{*}{$\begin{array}{c}13.851 \\
(0.001)^{* *}\end{array}$} \\
\hline WOM $>50-\leq 60$ & $147(72.8 \%)$ & $239(75.9 \%)$ & \\
\hline WOM $>60-\leq 70$ & $21(10.4 \%)$ & $53(16.8 \%)$ & \\
\hline \multicolumn{4}{|c|}{ Height of Mothers (CM) } \\
\hline Less than $(150) \mathrm{cm}$ & $41(20.3 \%)$ & $56(17.8 \%)$ & \multirow{3}{*}{$\begin{array}{c}0.556 \\
(0.757)\end{array}$} \\
\hline$(150-159) \mathrm{cm}$ & $98(48.5 \%)$ & $155(49.2 \%)$ & \\
\hline $160 \mathrm{~cm}$ and above & $63(31.2 \%)$ & $104(33.0 \%)$ & \\
\hline \multicolumn{4}{|l|}{ BMI (kg (cm²) } \\
\hline $\mathrm{BMI}<18.5$ & $22(10.9 \%)$ & $6(1.9 \%)$ & \multirow{3}{*}{$\begin{array}{c}23.968 \\
(0.000)^{* * *}\end{array}$} \\
\hline $\mathrm{BMI}=18.5<25$ & $171(84.7 \%)$ & $276(87.6 \%)$ & \\
\hline $\mathrm{BMI}=25<30$ & $9(4.5 \%)$ & $33(10.5 \%)$ & \\
\hline \multicolumn{4}{|c|}{ Gestational Age at Delivery } \\
\hline $\mathrm{G}<37$ weeks & $114(56.4 \%)$ & $60(19 \%)$ & \multirow{2}{*}{$\begin{array}{c}77.050 \\
(0.000)^{* * *}\end{array}$} \\
\hline $\mathrm{G} \geq 37$ weeks & 88 (43.6\%) & $266(81 \%)$ & \\
\hline
\end{tabular}

Statistical significance : ${ }^{* * *} \mathrm{P}<.001,{ }^{* *} \mathrm{p}<.01,{ }^{*} \mathrm{p}<.05$

All maternal characteristics shown in table 3 were significantly related with neonate birth weight except maternal age and parity, the result shown that birth weight rises as mothers' weight increases in other words 
big mothers' had big babies. There was a significant relation between the maternal weight and neonate birth weight, it was clear that initial weight of mother $(\leq 50$ $\mathrm{kg}$ ) of LBW neonates were nearly 4.33 times greater than that of LBW mothers who had weights $(>50-\leq 60)$. A difference was observed with respect to the body mass index, $84.7 \%$ mothers of low birth weight neonates had normal $\left(18.5 \leq \mathrm{BMI}<25 \mathrm{~kg} / \mathrm{cm}^{2}\right)$ and $9.4 \%$ mothers of low birth weight neonates had overweight $\left(25 \leq \mathrm{BMI}<30 \mathrm{~kg} / \mathrm{cm}^{2}\right)$. As expected preterm delivery had a strong influence on the birth weight, $56.4 \%$ mother of low birth weight neonates less than 37 weeks gestation as compared with $43.6 \%$ of those who had their neonates after 37 weeks.

Table 4: Distribution of Neonate birth weight and Maternal Antenatal care.

\begin{tabular}{|c|c|c|c|}
\hline $\begin{array}{l}\text { Antenatal care } \\
\text { Characteristics }\end{array}$ & $\begin{array}{c}\text { Low Birth } \\
\text { Weight (LBW) }\end{array}$ & $\begin{array}{l}\text { Normal Birth } \\
\text { Weight (NBW) }\end{array}$ & $\chi^{2}$ \\
\hline \multicolumn{4}{|c|}{ Number of ANC visits } \\
\hline $\mathrm{ANC}<4$ & $172(85.1 \%)$ & $180(57.1 \%)$ & \multirow{2}{*}{$\begin{array}{c}44.424 \\
(0.000)^{* * *}\end{array}$} \\
\hline $\mathrm{ANC} \geq 4$ & $30(14.9 \%)$ & $135(42.9 \%)$ & \\
\hline \multicolumn{4}{|c|}{ Weight gain of Mother (in Kg) } \\
\hline $\mathrm{WG}<5$ & $169(83.7 \%)$ & $25(7.9 \%)$ & \multirow{2}{*}{$\begin{array}{c}301.05 \\
(0.000)^{* * *}\end{array}$} \\
\hline $\mathrm{WG} \geq 5$ & $33(16.3 \%)$ & $290(92.1 \%)$ & \\
\hline \multicolumn{4}{|c|}{ Use Iron Calcium } \\
\hline Yes & $97(48 \%)$ & $302(95.9 \%)$ & \multirow{2}{*}{$\begin{array}{c}160 \\
(0.000)^{* * *}\end{array}$} \\
\hline No & $105(52 \%)$ & $13(4.1 \%)$ & \\
\hline \multicolumn{4}{|c|}{ Presence of Illness } \\
\hline Yes & $56(27.7 \%)$ & $24(7.6 \%)$ & \multirow{2}{*}{$\begin{array}{c}38.031 \\
(0.000)^{* * *}\end{array}$} \\
\hline No & $146(72.3)$ & 291(92.4\%) & \\
\hline
\end{tabular}

Statistical significance : ${ }^{* * *} \mathrm{P}<.01,{ }^{* *} \mathrm{p}<.05,{ }^{*} \mathrm{p}<.001$

The relationship between maternal antenatal behavioral variables and neonatal birth weight was analyzed in Table 4. All the variables displayed in the table were significantly associated with neonatal birth weight. There was a significant relation between antenatal care and LBW neonate, $85.1 \%$ of women with 3 antenatal care visits had low birth weight neonates related to $14.9 \%$ of those who had more than 3 antenatal visit $.83 .7 \%$ women with less than $5 \mathrm{~kg}$ weight gain during pregnancy had low birth weight neonates relative to $16.3 \%$ of those who had more than or equal to $5 \mathrm{~kg}$ weight gain, 52\% women who did not use prenatal supplements such as Iron and Calcium during pregnancy were more likely to have low birth weight neonates. Likewise, woman who presented no illness during pregnancy have bigger neonates relative to those who had some illness; $27.7 \%$ mothers of LBW neonates had illness during pregnancy as compared to $72.3 \%$ mothers had no illness.
Table 5 shows the result of Logistic regression model for the low birth weight presented as odds ratios. The first model examines the variation in the birth weight as a function of socio-demographic variables this is the baseline model and the variables included education of mother and father, occupation of father, family income. Second model included maternal reproductive health factors. In the third model maternal antenatal care variables.

Results from the Model 1 , maternal education was the strongest predictor of the odds of having a LBW neonate in this model, the effect of maternal education had the expected direction with mothers whose educational attainment was below secondary education having significantly higher risk for having a low weight neonates $(\mathrm{OR}=2.3 .19 ; \mathrm{CI}=1.34,3.93)$; mother with a graduate level education so reduced odds of having a low weight neonates $(\mathrm{OR}=2.24 ; \mathrm{CI}=1.36-3.67)$ and 
Table 5: Multivariate Logistic regression analysis to assess the association between selected factors and low birth weight.

\begin{tabular}{|c|c|c|c|}
\hline Variables/categories & $\begin{array}{cl}\text { Model 1 } \\
\text { [odds ratio }(95 \% \mathrm{CI})]\end{array}$ & $\begin{array}{cl}\text { Model 2 } \\
\text { [odds ratio }(95 \% \mathrm{CI})]\end{array}$ & $\begin{array}{c}\text { Model 3 } \\
\text { [odds ratio }(95 \% \mathrm{CI})]\end{array}$ \\
\hline \multicolumn{4}{|c|}{ Maternal Level of Education } \\
\hline High school & $2.30(1.35,3.93)^{* *}$ & $2.62(1.42,4.82)^{* *}$ & $1.19(0.44,3.20)$ \\
\hline Intermediate (Ref) & 1.00 & 1.00 & 1.00 \\
\hline $\begin{array}{l}\text { Graduate \& Professional } \\
\text { degree }\end{array}$ & $2.24(1.37,3.68)^{* *}$ & $2.49(1.43,4.37)^{* *}$ & $10.47(4.46,24.58)^{* * * *}$ \\
\hline Post graduate & $1.14(0.52,2.5)$ & $1.26(0.54,3.01)$ & $4.51(1.39,14.60)^{*}$ \\
\hline \multicolumn{4}{|l|}{ Education of Father } \\
\hline High school & $0.52(0.26,1.04)$ & $0.68(0.29,1.4)$ & $0.39(0.11,1.40)$ \\
\hline Intermediate(Ref ) & 1.00 & 1.00 & 1.00 \\
\hline $\begin{array}{l}\text { Graduate \& Professional } \\
\text { degree }\end{array}$ & $0.66(0.41,1.06)$ & $0.78(0.45,1.35)$ & $1.45(0.68,3.10)$ \\
\hline Post graduate & $1.17(0.56,2.44)$ & $1.36(0.58,3.17)$ & $1.59(0.53,4.69)$ \\
\hline \multicolumn{4}{|l|}{ Occupation of father } \\
\hline Student & $0.69(0.37,1.31)$ & $1.52(0.73,3.17)$ & $1.89(0.70,5.05)$ \\
\hline Private job (Ref) & 1.00 & 1.00 & 1.00 \\
\hline Government job & $0.42(0.19,0.94)^{*}$ & $0.55(0.28,1.07)$ & $0.63(0.25,1.58)$ \\
\hline Daily wage worker & $1.53(0.57,4.14)$ & $2.52(0.99,6.43)$ & $2.58(0.57,11.68)$ \\
\hline \multicolumn{4}{|l|}{ Family income } \\
\hline I (Less than 10000) & $0.95(0.47,1.87)$ & $0.85(0.39,1.85)$ & $2.31(0.76,7.08)$ \\
\hline II (10000-15000) & $1.30(0.74,2.31)$ & $1.37(0.73,2.59)$ & $2.73(1.11,6.75)^{*}$ \\
\hline III (15000-20000) & $1.03(0.62,1.69)$ & $0.89(0.51,1.59)$ & $1.89(0.88,4.03)$ \\
\hline IV (20000 \& Above) (Ref) & 1.00 & 1.00 & 1.00 \\
\hline \multicolumn{4}{|l|}{ Sex of Neonate } \\
\hline Male (Ref) & & 1.00 & 1.00 \\
\hline Female & & $1.69(1.09,2.51)^{*}$ & $2.23(1.25,3.99)$ \\
\hline \multicolumn{4}{|l|}{ Parity } \\
\hline 1-2(Ref) & & 1.00 & 1.00 \\
\hline $3-6$ & & $2.42(1.18,4.96)^{* *}$ & $1.21(0.43,3.42)$ \\
\hline \multicolumn{4}{|l|}{ Gestational Age } \\
\hline$G^{3} 37$ weeks(Ref) & & 1.00 & 1.00 \\
\hline$G<37$ weeks & & $7.67(4.85,12.10)^{* * *}$ & $5.39(2.84,10.17)^{* * *}$ \\
\hline Maternal Weight & & $0.86(0.79,0.93)^{* * *}$ & $1.03(0.91,1.17)$ \\
\hline
\end{tabular}

Statistical significance : ${ }^{* * *} \mathrm{P}<.01,{ }^{* *} \mathrm{p}<.05,{ }^{*} \mathrm{p}<.001$ 


\begin{tabular}{|c|c|c|}
\hline Maternal Height & $1.02(0.97,1.06)$ & $1.01(0.94,1.09)$ \\
\hline Weight gain & & $0.59(0.44,0.79)^{* * *}$ \\
\hline \multicolumn{3}{|l|}{ BMI } \\
\hline $\mathrm{BMI}<18.5$ & & $47.37(4.19,534.97)^{* *}$ \\
\hline $\mathrm{BMI}=18.5<25(\operatorname{Ref})$ & & 1.00 \\
\hline $\mathrm{BMI}=25<30$ & & $5.22(1.12,24.40)^{*}$ \\
\hline \multicolumn{3}{|c|}{ Number of ANC visits } \\
\hline $\mathrm{ANC}<3$ & & $11.98(3.53,40.65)^{* * *}$ \\
\hline $\mathrm{ANC}=3$ & & $1.99(0.99,3.99)$ \\
\hline ANC $>3$ (Ref) & & 1.00 \\
\hline \multicolumn{3}{|l|}{ Use Iron Calcium } \\
\hline No & & $58.93(22.63,153.43)^{* * *}$ \\
\hline Yes(Ref) & & 1.00 \\
\hline \multicolumn{3}{|l|}{ Presence of Illness } \\
\hline Yes & & $3.70(1.57 .8 .72)^{* * *}$ \\
\hline No (Ref) & & 1.00 \\
\hline
\end{tabular}

Statistical significance: $* * * \mathrm{P}<.001,{ }^{*} \mathrm{p}<.01,{ }^{*} \mathrm{p}<.05 ;{ }^{\circledR}=$ Reference category; $[1]=$ odds ratio of the reference category.

mother with a post graduate and above education showed reduced odds of having low birth weight neonates(OR=1.14; $\mathrm{CI}=0.52-2.50)$ although it was not statistically significant. The effect of father education at post graduate and above, increased odds of having low birth weight neonates (OR=1.69; $\mathrm{CI}=0.55-2.44)$, it was not statistically significant. Fathers who had a occupation as a student, statistically significant, odds of having a low birth weight neonates $(\mathrm{OR}=1.14$; $\mathrm{CI}=0.52-$ 2.50) and who had occupation as government job presented in the model, reduced odds of having normal birth weight neonates $(\mathrm{OR}=0.42$; $\mathrm{CI}=0.18-0.94)$, where as daily wage worker presented odds $(\mathrm{OR}=1.53$; $\mathrm{CI}=0.56-4.13)$ it was not statistically significant. Family income of second category of house, odds of having a low birth weight neonates ( $\mathrm{OR}=1.30$; $\mathrm{CI}=0.73-2.31$ ), where as third category score presented odds $(\mathrm{OR}=1.02$; $\mathrm{CI}=0.62-1.69$ ) although it was not statistical significant.

Table 5 shows the result of Logistic regression model for the low birth weight presented as odds ratios. The first model examines the variation in the birth weight as a function of socio-demographic variables this is the baseline model and the variables included education of mother and father, occupation of father, family income. Second model included maternal reproductive health factors. In the third model maternal antenatal care variables.

Results from the Model 1 ,maternal education was the strongest predictor of the odds of having a LBW neonate in this model, the effect of maternal education had the expected direction with mothers whose educational attainment was below secondary education having significantly higher risk for having a low weight neonates $(\mathrm{OR}=2.3 ; \mathrm{CI}=1.34,3.93)$; mother with a graduate level education so reduced odds of having a low weight neonates $(\mathrm{OR}=2.24 ; \mathrm{CI}=1.36-3.67)$ and mother with a post graduate and above education showed reduced odds of having low birth weight neonates $(\mathrm{OR}=1.14 ; \mathrm{CI}=0.52-2.50)$ although it was not statistically significant. The effect of father education at post graduate and above, increased odds of having low birth weight neonates ( $\mathrm{OR}=1.69$; $\mathrm{CI}=0.55-2.44)$, it was not statistically significant. Fathers who had a occupation as a student, statistically not significant, odds of having a normal birth weight neonates (OR $=0.69$; $\mathrm{CI}=0.37-1.31$ ) and who had occupation as government job presented in the model, reduced odds of having normal birth weight neonates(OR=0.42; $\mathrm{CI}=0.18-0.94)$, where as daily wage worker presented odds $(\mathrm{OR}=1.53$; $\mathrm{CI}=0.56-4.13$ ) it was not statistically significant. Family income of second category, odds of having a low birth 
weight neonates $(\mathrm{OR}=1.30$; $\mathrm{CI}=0.73-2.31)$, where as third category score presented odds $(\mathrm{OR}=1.03$; $\mathrm{CI}=0.62-$ 1.69) although it was not statistical significant.

All maternal factors in Model II, except occupation of father and maternal height were significant in predicting the odds of having a low birth weight neonate. Female neonates $(\mathrm{OR}=2.42 ; \mathrm{CI}=1.28-4.96)$ were significantly more likely to be low birth weight related to male neonates. Women having 3-6 children are more likely to have low birth weight neonates $(\mathrm{OR}=2.42$; $\mathrm{CI}=1$.18.4.96) relative to those with 1-2 children. Weight of mothers was significantly related to odds of having a normal weight baby in other words, the higher the weight of women the less likely they are to have low birth weight neonates. The gestational age at delivery was the variable most strongly associated with the risk of having low birth weight neonates mothers who delivered before 37 completed weeks of gestation had greatly increases odds $(\mathrm{OR}=7.66)$ of having low weight neonate compared to the mothers who had term pregnancy Model 3 includes the set of variables levels in the previous two model and the controlled for the maternal antenatal care variable.

Weight gain of mother was significantly related to the odds of having a normal weight babies. Body mass index of mothers was important risk factor for low birth weight neonates mother who had under weight $(\mathrm{OR}=47.37 ; \mathrm{CI}=4.19-534.97)$ and overweight $(\mathrm{OR}=5.22 ; \mathrm{CI}=1.12-24.40)$ had significantly odds of having low birth weight neonates relative to women who had normal weight. Mothers who had less than 3 antenatal care visit also had increase odds for low birth weight neonates ( $\mathrm{OR}=11.98$; $\mathrm{CI}=3.5-40.65)$ compared to mothers who had greater than 3 visits and mothers who had 3 antenatal care visit, decreased odds for low birth weight neonates $(\mathrm{OR}=1.99$; $\mathrm{CI}=0.99-3.99)$ but the result was not statistical significant. The gestational age at delivery was associated with the risk of having low birth weight neonates. Mothers who delivered before 37 completed weeks of gestation had increases odds (OR=5.39; $\mathrm{CI}=2.8-10.17$ ) having a low weight neonates compared to the Mother's who had term pregnancy. Mothers who did not use iron and calcium supplements was most strongest predictor of odds of having a low birth weight neonates in the final model. Mothers who did not use Iron and Calcium supplement presented significant increase odds (OR=59.98; $\mathrm{CI}=22.63-153.43$ ) having a low weight baby is compared to mother who used them. Women, who did not suffering from health problem during their pregnancy had significantly odds ( $\mathrm{OR}=3.70$; $\mathrm{CI}=1.57-8.72)$ having a low birth weight neonate. The result of maternal education and family income changed in the opposite direction with the inclusion of antenatal variable in the third model, with mothers of graduate and postgraduate level education having significantly increased odds having a low birth weight neonates and family income of second category was significantly related to the higher odds of having a low birth weight neonates.

\section{DISCUSSION}

This study was undertaken to study the influence of maternal factors in low birth weight neonates. The prevalence of Low Birth Weight (LBW) in the present study was $39.07 \%$ and according to NFHS- 4 report the prevalence of low birth weight in India is found to be $16.9 \%$. Maternal age does not have any statistical significance in our study as $(\mathrm{p}=0.15)$. Similar results was obtained from the studies done by Ravi kumar bhaskar et al. and Kamal Prasad kandel, but contrary to the earlier studies done by Aboobucker Haalisha et al. According to Agarwal et al., they found that 57.14\% low birth weight babies is found among mothers below 20 years age group and $53.34 \%$ more than 35 years age group.

Education of father and mother were divided into 3 groups- high school, intermediate, graduate \& professional degree, post graduate \& above. Association of education and birth weight is statistically significant. Among the mothers who were having low birth weight neonates, 35.1\% had below secondary level education and also $19.3 \%$ fathers who had below secondary level education This is similar to the study done by Shantanu Sharma et al. and according to Chaithra A. et al., 33.3\% women done primary and $15 \%$ done high school level education. But different result found by Raja $\mathrm{M}$ et al. There is statistical significance between birth weight of neonates and father occupation. About $13.4 \%$ of fathers who had LBW neonates were labourers and $64.9 \%$ of fathers who had doing private job. This is similar to the study done by Leila Hussen et al., father's occupation was significantly associated with low birth weight. Farmer fathers were three times more likely to have low birth weight (AOR: 3.1; 95\% CI 1.5, 6.3) as compared to fathers doing government job.

There is no statistical significance between birth weight of neonates and family income of house $(p=0.257)$ and it is similar to the studies done by Ravi kumar bhaskar et al. and according to Leila Hussen et al. family income affect low birth weight babies. There is a highly statistical significance between maternal weight and birth weight of neonates $(\mathrm{p}<0.01)$. In the study, mothers having weight $<50 \mathrm{~kg}$, low birth weight 
incidence is $16.8 \%$, while mothers having weight $>50$ $\mathrm{kg}$ is $83.2 \%$. This is similar to the studies done by Aboobucker Haalisha et al. (and Leila hussen et al. Ravi kumar bhaskar et al. was found in their study, $50.31 \%$ mothers having weight $\leq 45 \mathrm{~kg}$.

There is no statistical significance between birth weight of neonates and maternal height $(p=0.757)$. This is similar to the studies done by Chaithra A. et al and Pawar A et al. But Agarwal A, Sharma V. found different result in their study that maximum number of low birth weight babies are delivered from short statured mother (height $<145 \mathrm{~cm}$ ) and it is similar to the studies done by Kamal Prasad kandel , Ravi kumar bhaskar et al. There is a highly statistical significance between birth weight of neonates and BMI of mothers $(\mathrm{P}<.000)$. This is similar to the studies done by Kamal Prasad kandel and different result found by Ravi kumar bhaskar et al. \& Haalisha and aboobuckar Jahufer $(\mathrm{p}<.093)$.

In our study, parity has no statistically significant association with regards to birth weight of neonates. This is similar to the studies done by Kamal Prasad kadel, Priyanka Anand et al. But Haalisha and aboobuckar Jahufer has found their studies parity has affect the birth weight of baby $(\mathrm{p}<.013)$ and similar to the studies done by Sri Eka Purwanengsi et al. There is significant association between sex of baby and birth weight. Similar results was obtained from the studies done by M. Sheeba Apoorva et al. and according to Priyanka Anand et al. they found in their study no relation between sex of neonate and birth weight $(\mathrm{p}<.799)$. Gestational age had a strong influence on the birth weight of neonates , $56.4 \%$ of LBW neonates were born to gestational age below 37 weeks. Similar result was obtained from the studies done by Agarwal A, Sharma V., Raja M et al and Sri eka Purwanengsi et al. There is a highly statistical significance between birth weight of neonates and number of ANC visit by mothers and similar result found by Ravi kumar bhaskar et al. and by Shantanu Sharma et al. but in divergence with Priyanka Anand et al. Weight gain during pregnancy was found to be highly significance associated with LBW neonate. According to Kamal Prasad kandel,. they found that $17.4 \%$ mothers, who had weight gain during pregnancy less than $10 \mathrm{~kg}$, had highest low birth weight babies. Use of Iron and Calcium supplement during pregnancy is one of the most important factor in LBW neonates 52\% women who did not use prenatal supplements were more likely to have low birth weight neonates. Similar result was obtained from the studies done by Ravi kumar bhaskar et al.and
Shantanu Sharma et al. in divergence with Priyanka et al. There is a highly statistical significance between birth weight of neonates and mothers had illness during pregnancy; $27.7 \%$ mothers of LBW neonates had illness during pregnancy as compared to $72.3 \%$ mothers had no illness Similar result was obtained from the studies done by Ravi kumar bhaskar et al.and M. sheeba Apoorva et al. in divergence with Priyanka Anand et al. $(\mathrm{p}<0.116)$.

\section{CONCLUSION}

This study contributes to the understanding of the individual and collective effect of socio demographic and maternal factors influencing neonate birth weight. It identified the level of maternal knowledge and perception about neonate birth weight and thus highlighted possible area of intervention to promote better health outcomes for pregnant women. This study shows that maternal antenatal care variables have the strongest influence in determining the birth weight of neonate among the respondents. However, sociodemographic and maternal health factors are significantly associated with low birth weight. It has concluded LBW was found to be affected by education of mother and father, maternal weight $<50$ $\mathrm{kg}$, maternal weight gain $<5 \mathrm{~kg}$, pre pregnancy $\mathrm{BMI}<($ $18.5 \mathrm{~kg} / \mathrm{cm} 2)$, less than three antenatal visit by mothers, less than 37 weeks gestational, low socio economic status and presence of any illnesses. It is suggested that programs that work to reduce the rate of low birth weight neonates should focus on improving maternal lifestyle choices by increasing access, utilization and quality of care. Socio- cultural factors influenced the growth of foetus and outcomes of pregnancies. Most women lacked knowledge of the pregnancy risk factor that adversely affect neonatal birth weight and the exact mechanism by which the risk factors act to cause adverse effects. Health education for the pregnant women socioeconomic development, maternal nutrition, and increasing the use of health services during pregnancy, are all important for reducing LBW. This way healthier neonates are produced who have a better chance of surviving and becoming tomorrow's. wealth.

\section{ACKNOWLEDGEMENT}

We are thankful to Inst. Ethical Committee Chairperson (V. M. Gupta) and Head of Obst. \& Gynecology, IMS (Prof. Madhu Jain) give me permission to collect the data from postnatal ward and also baby delivered mothers without their cooperation, it was not easy task to collect the data. 


\section{REFERENCES}

1. Aboobucker Haalisha and aboobuckar Jahufer- Logistic regression methodology for assessing the contributing factor of low birth weight, International Journal of statistics and applied mathematics. 2018; 3(5):134-139.

2. Agarwal A, Sharma V. To Study the maternal factors which determine the low birth weight babies. International Journal of Pediatric Research. January 2017, Vol-4,Issu-01:1-11.

3. Anant Pawar, Durgesh Kumar. Maternal factors associated with low birth weight: 2 . a case control study in rural Kerala. Int $J$ Community Med International Journal of Community Medicine and Public Health, October 2017, Vol 4 , Issue 10:3793-5.

4. Arun K Koirala, Dharma N Bhatta. Low birth weight babies among the hospital deliveries in Nepal: Hospital based study. International Journal of women's health. 2015, 581- 585.

5. Chaithra A. Mahantappa A.. Sharada B. Menasin Kai. A study on maternal factors affecting low birth weight in institutional deliveries, International Journal of Reproduction, Contraception, Obstetrics and Gynaecology. 2020 Oct:9(10): 4245-4249.

6. Kamal Prasad Kandel, Sindhu Kafle. Risk factor associated with low birth weight among the deliveries at Bharatpur Hospital. J Nepal health Res. Counci. 2017 may-Aug;25(36):169-73.

7. Leila Hussen, Blen Kasshun, Shemsu Kadir, Bahredin Abdala and Mubarak Yesse. Maternal Factors Associated with Low Birth Weight among Term Newborns in South Ethiopia: A CaseControl Study. International Journal of Medical Research \& Health science. 2021, 10(7): 69-77.

8. Lumbani Tshotetsi, Loveness Dzikiti, Precious Hajison, and Shingairai Feresu. "Maternal factors contributing to low birth weight deliveries in Tshwane District, South Africa." PLOSONE 14(3):e0213058.https://Doi.org/10.1371/journal. pone.0213058, March 1, 2019, pp.-1-13.

9. M. Sheena Apoorva, Vimla Thomas,B. Kiranmai. A cross-sectional study on socio demographic and maternal factors associated with lowest weight baby among institutional deliveries in a territory Care Hospital, Hyderabad, Telangana, International Journal of community medicine and Public Health, Nov 2018; 5(11): 4901- 4904.

10. Maheshwari K., Neha Sharma. Magnitude, risk factors and outcome of low birth weight babies admitted to new natal Intensive Care Unit of territory care centre in Puducherry India, International Journal of contemporary Pediatrics. 2020 June;7(6):1389-1393.

11. Priyanka Anand, Rahul Gupta, Jaspreet Kour Sudan. Prevalence of low birth weight and associated maternal risk factor among the term units during normal delivery in Jammu , J \& K, International Journal of health science and research. Volum 9 ; issue: 8 ;August 2019.

12. Ravi Kumar Bhaskar, Krishna Kumar Deo, Uttam Neupane, Subhadra Chaudhary Bhaskar, Birendra Kumar Yadav, Hanoon P. Pokharel, hand Paras Kumar Pokharel - Case control study on risk factors associated with low birth weight babies in Eastern Nepal. International Journal of Pediatrics. 2015.

13. Raja M., Senthamarai Kannan K. and V. Danesh Kumar. Regression modelling for maternal determinants of low birth weight, International journal of statistics and system November 3 (2017), pp.585- 592.

14. Sanjay Rode. The socio economic determinants of low birth weight babies of slums in Mumbai Metropolitan region, business excellence and Management, June 2015.

15. Srieka Purwanengsi, Kuntoro, Windypurnomo, Bambang Widjanarkootok the modelling level of birth weight using a maximum likelihood estimation of generalized method of moment. Journal of applied environmental and biological science. 2016 6(7)125-128.

16. Shantanu Sharma, Sonali Maheshwari and Sunil Mehra. Association between maternal dietary diversity and low birth weight in Central India: A case control study. Journal of nutrition and metabolism. May 2021,pp-1-8.

17. Srinivas Prudhivi Revanasiddappa BhosgiMaternal factors influencing low birth weight babies. International Journal of Contemporary Pediatrics. 2015 Nov;2(4):287-296. 